\title{
Synergistic Effects of ACE Insertion/Deletion and GNB3 C825T Polymorphisms on the Efficacy of PDE-5 Inhibitor in Patients with Pulmonary Hypertension
}

\author{
Rintaro Nishimura ${ }^{a}$ Nobuhiro Tanabe ${ }^{a, b} \quad$ Ayumi Sekine $^{a}$ Hajime Kasai $^{a}$ \\ Rika Suda $^{a}$ Fumiaki Kato $^{a}$ Takayuki Jujo $^{a, b}$ Toshihiko Sugiura ${ }^{a}$ \\ Ayako Shigeta $^{a, b}$ Seiichiro Sakao ${ }^{a}$ Koichiro Tatsumi ${ }^{a}$ \\ Departments of a Respirology and ${ }^{\mathrm{b}}$ Advanced Medicine in Pulmonary Hypertension, Graduate School of Medicine, \\ Chiba University, Chiba, Japan
}

\section{Key Words}

Pulmonary hypertension - Gene polymorphism - ACE - GNB3 . Phosphodiesterase-5 inhibitor

\begin{abstract}
Background: The insertion/deletion (I/D) polymorphism in the angiotensin-converting enzyme gene (ACE) and the C825T polymorphism in the $\mathrm{G}$-protein $\beta 3$ subunit gene (GNB3) are associated with the efficacy of phosphodiesterase-5 inhibitor (PDE-5I) in erectile dysfunction. In addition, GNB3 genotypes could be associated with clinical worsening in pulmonary hypertension $(\mathrm{PH})$ treated with PDE-5I. However, no studies have described the synergistic effects of gene polymorphisms on drug efficacy in patients with $\mathrm{PH}$. Objectives: We aimed to examine the effects of combined ACE/GNB3 polymorphisms on the efficacy of PDE-5I in patients with PH. Methods: This was a retrospective uncontrolled study. Ninety patients with pulmonary arterial hypertension (PAH) or chronic thromboembolic PH (CTEPH) were treated with PDE-5I. Freedom from clinical worsening and pre- and post-treatment parameters, including the 6-min walk distance (6MWD) and serum brain natriuretic peptide
\end{abstract}

\section{KARGER}

E-Mail karger@karger.com

www.karger.com/res
(BNP) levels, were compared between patients with ACE/GNB3 II/TT and non-II/TT genotypes. Results: Time to clinical worsening was significantly longer in patients with the II/TT genotype than in those with the non-II/TT genotype (5-year freedom from clinical worsening: 100 vs. $48.8 \%$, respectively; $p=0.018$ ), even in patients with CTEPH alone. Post-treatment 6MWD and BNP levels in patients with the II/ $\Pi T$ genotype tended to be better than those in patients with the non-II/TT genotype. The ACE/GNB3 genotype was a significant predictor of clinical worsening, even after adjusting for pulmonary vascular resistance and 6MWD. Conclusions: ACE and GNB3 polymorphisms may synergistically influence the efficacy of PDE-5I in patients with $\mathrm{PH}$.

(c) 2016 S. Karger AG, Basel

\section{Introduction}

Pulmonary hypertension $(\mathrm{PH})$ is defined as having a mean pulmonary arterial pressure (Ppa) of $\geq 25 \mathrm{~mm} \mathrm{Hg}$ at rest as assessed by right heart catheterization $[1,2]$. Clinically, $\mathrm{PH}$ has been classified into 5 categories [3]. Among them, pulmonary arterial hypertension $(\mathrm{PAH})$ is 
characterized by progressive vascular remodeling, which can result in right heart failure and death [2]. Chronic thromboembolic $\mathrm{PH}$ (CTEPH) results from pulmonary arterial obstruction by unresolved, organized thrombi. In addition, small vessel diseases similar to $\mathrm{PAH}$ also exist with CTEPH [4]. Therefore, medical therapy for PAH has been applied in patients with CTEPH who have inoperable disease or persistent $\mathrm{PH}$ after pulmonary endarterectomy [5]. The effects of phosphodiesterase-5 inhibitor (PDE-5I), which has been shown to be efficient in treating $\mathrm{PAH}$, are accomplished by enhancing the downstream response of nitric oxide (NO)-mediated vasodilatation. In addition, sildenafil, a PDE-5I, may have beneficial effects on platelet activation, pulmonary vascular remodeling, and cardiac function [6].

Angiotensin-converting enzyme (ACE) is a key factor in the renin-angiotensin system, which regulates blood flow and plays a fundamental role in the onset and/or progression of cardiovascular diseases [7-9]. The ACE gene contains a polymorphism based on the presence (insertion, I) or absence (deletion, D) of a 287-bp sequence of DNA in intron 16 [10]. We previously reported that the $A C E \mathrm{D}$ allele may be a factor predicting poor prognosis in medically treated patients with CTEPH [11].

Guanine nucleotide-binding proteins (G proteins) are ubiquitously expressed essential proteins that mediate signal transduction. The G-protein complex consists of three subunits: $\alpha, \beta$, and $\gamma$. Siffert et al. [12] reported a silent C825T polymorphism in exon 10 of the G-protein $\beta 3$ subunit (GNB3) gene encoding the G-protein $\beta 3$ subunit [13].

The drug response to sildenafil in patients with erectile dysfunction differs depending on the ACE I/D and GNB3 C825T genotypes [14]. In addition, the GNB3 C825T polymorphism influences the efficacy of sildenafil in the treatment of $\mathrm{PH}$ [15]. We thus sought to investigate the association between the combined ACE/GNB3 polymorphisms and the clinical efficacy of PDE-5I in patients with $\mathrm{PH}$.

\section{Materials and Methods}

\section{Study Design and Patients}

This study was a retrospective, single-center cohort investigation. Ninety patients with either PAH $(\mathrm{n}=32)$ or CTEPH $(\mathrm{n}=58)$ were treated with a PDE-5I (sildenafil: $\mathrm{n}=74$; tadalafil: $\mathrm{n}=16$ ) at Chiba University Hospital between September 2003 and December 2013. PAH or CTEPH was defined as a mean Ppa of $\geq 25 \mathrm{~mm}$ $\mathrm{Hg}$ with normal wedge pressure on right heart catheterization. In patients with $\mathrm{PAH}$, the inclusion criteria further contained a normal or mottled perfusion pattern with normal ventilation on ven- tilation-perfusion scans. In patients with CTEPH, the inclusion criteria needed the presence of symptoms such as dyspnea on exertion for more than 6 months, segmental or larger lung perfusion defects concomitant with normal ventilation scans, and chronic thromboembolic findings confirmed on pulmonary angiography.

\section{Determination of the ACE and GNB3 Genotypes}

Genomic DNA was extracted from $200 \mu \mathrm{l}$ of peripheral whole blood using a QIAamp DNA Mini Kit (Qiagen, Valencia, Calif., USA), according to the manufacturer's protocols. Genotyping was performed by polymerase chain reaction with an ABI 7300 Prism Sequence Detection System (Applied Biosystems, Carlsbad, Calif., USA). DNA amplification and genotype determination were performed in a single assay using Taqman SNP genotyping assays (Applied Biosystems), with allele-specific fluorogenic probes. Detection of the ACE I/D polymorphism was carried out using primers and methods described by Koch et al. [16]. Genotypes for the C825T polymorphism of the GNB3 gene were determined as previously described [15]. The patients were blinded to the genotype data for the duration of the trial. The baseline and post-treatment parameters were compared between patients with $A C E / G N B 3$ II/ TT and non-II/TT genotypes.

\section{Study Protocol}

Although sildenafil was approved in Japan for the treatment of $\mathrm{PAH}$ in 2008, it has been available at our institution since 2003 in a doctor-oriented trial. The disease severity was evaluated prior to administration of the PDE-5I and after treatment within 3 months according to the following parameters: the systolic Ppa estimated on Doppler echocardiography (sPpa), the 6-min walk distance (6MWD) test, serum levels of brain natriuretic peptide (BNP), and World Health Organization (WHO) functional class. Right heart catheterization data obtained within 2 months of initiation of PDE-5I treatment were also evaluated. Starting from the initiation of PDE-5I treatment, the time to clinical worsening defined as death or hospitalization due to right heart failure was compared between genotype groups. Patients who were treated with additional PAH therapies and patients with CTEPH who received surgery or balloon pulmonary angioplasty were censored at that time. The baseline characteristics predicting freedom from clinical worsening were also investigated.

The study protocol was approved by the Research Ethics Committee of Chiba University School of Medicine, and written informed consent was given by each patient.

\section{Statistical Analysis}

All data are expressed as the mean \pm standard deviation (SD). Genotype frequencies were compared between patients and controls using the $\chi^{2}$ test. The Hardy-Weinberg equilibrium for genotype distribution was estimated by the $\chi^{2}$ test. Comparisons between the two groups were performed by the unpaired $t$ test, Wilcoxon's rank-sum test, or the $\chi^{2}$ test. Freedom from clinical worsening curves between the two groups were derived from the Kaplan-Meier method and compared by the log-rank test. To determine whether the gene polymorphism was an independent predictor, 6MWD and pulmonary hemodynamic parameters were examined using a multivariate Cox proportional hazard analysis. Differences with $p$ values $<0.05$ were considered significant. All statistical analyses were performed using JMP 9.0.0 (SAS Institute Inc., Tokyo, Japan). 
Table 1. Characteristics of patients with PAH or CTEPH

\begin{tabular}{|c|c|c|c|c|}
\hline$A C E / G N B 3$ & $\begin{array}{l}\text { All } \\
(n=90)\end{array}$ & $\begin{array}{l}\text { II/TT } \\
(\mathrm{n}=15)\end{array}$ & $\begin{array}{l}\text { Non-II/TT } \\
(\mathrm{n}=75)\end{array}$ & $\mathrm{p}$ \\
\hline Age, years & $54.2 \pm 14.0$ & $48.9 \pm 9.32$ & $55.3 \pm 14.6$ & 0.03 \\
\hline Female/male & $68 / 22$ & $11 / 4$ & $57 / 18$ & 0.83 \\
\hline Disease (PAH/CTEPH) & $32 / 58$ & $3 / 12$ & $29 / 46$ & 0.17 \\
\hline Mean Pra, mm Hg & $7.24 \pm 6.25$ & $5.50 \pm 2.81$ & $7.61 \pm 6.72$ & 0.33 \\
\hline Mean Ppa, mm Hg & $48.0 \pm 12.1$ & $46.8 \pm 7.46$ & $48.3 \pm 12.9$ & 0.59 \\
\hline $\mathrm{CI}, \mathrm{l} / \mathrm{min} / \mathrm{m}^{2}$ & $2.54 \pm 0.68$ & $2.54 \pm 0.45$ & $2.54 \pm 0.72$ & 0.76 \\
\hline PVR, Wood units & $10.8 \pm 5.0$ & $10.4 \pm 2.9$ & $10.9 \pm 5.4$ & 0.99 \\
\hline $\mathrm{PaO}_{2}$, Torr & $61.9 \pm 13.4$ & $59.7 \pm 10.1$ & $62.4 \pm 14.0$ & 0.69 \\
\hline Pretreatment (monotherapy/combination) & $53 / 37$ & $8 / 7$ & $29 / 46$ & 0.29 \\
\hline \multicolumn{5}{|l|}{$6 \mathrm{MWD}, \mathrm{m}$} \\
\hline Before treatment & $358 \pm 92.7$ & $375 \pm 91.9$ & $355 \pm 93.3$ & 0.48 \\
\hline After treatment & $380 \pm 89.9$ & $404 \pm 51.1$ & $375 \pm 96.0$ & 0.27 \\
\hline$\Delta 6 \mathrm{MWD}$ & $24.0 \pm 69.3$ & $38.1 \pm 53.1$ & $20.8 \pm 72.5$ & 0.9 \\
\hline \multicolumn{5}{|l|}{ sPpa, mm Hg } \\
\hline Before treatment & $84.7 \pm 25.5$ & $82.0 \pm 28.9$ & $85.3 \pm 25.0$ & 0.67 \\
\hline After treatment & $73.6 \pm 26.0$ & $67.3 \pm 35.6$ & $74.7 \pm 24.2$ & 0.39 \\
\hline$\Delta \mathrm{sPpa}$ & $-10.6 \pm 18.7$ & $-11.2 \pm 24.8$ & $-10.4 \pm 17.6$ & 0.72 \\
\hline \multicolumn{5}{|l|}{ WHO functional class (I/II/III/IV) } \\
\hline Before treatment & $0 / 29 / 46 / 15$ & $0 / 5 / 8 / 2$ & $0 / 24 / 38 / 13$ & 0.93 \\
\hline After treatment & $0 / 45 / 42 / 3$ & $0 / 10 / 5 / 0$ & $0 / 35 / 37 / 3$ & 0.32 \\
\hline \multicolumn{5}{|l|}{$\mathrm{BNP}, \mathrm{pg} / \mathrm{ml}$} \\
\hline Before treatment & $323 \pm 419$ & $244 \pm 350$ & $337 \pm 430$ & 0.25 \\
\hline After treatment & $192 \pm 273$ & $105 \pm 161$ & $208 \pm 288$ & 0.19 \\
\hline \multicolumn{5}{|l|}{$\mathrm{BNP}<100$ pg/ml, \% } \\
\hline Before treatment & 34.9 & 53.9 & 31.5 & 0.12 \\
\hline After treatment & 59.0 & 84.6 & 54.3 & 0.04 \\
\hline
\end{tabular}

Values are expressed as the mean $\pm \mathrm{SD}$ or $\mathrm{n}$. Pra $=$ Right atrial pressure; $\mathrm{CI}=$ cardiac index, $\mathrm{PaO}_{2}=$ arterial oxygen tension; $\Delta$ = post-treatment data - pretreatment data.

\section{Results}

Patient characteristics at baseline are shown in table 1. The mean age was $54.2 \pm 14.0$ years, and there were more women than men. The mean Ppa and pulmonary vascular resistance (PVR) were $48.0 \pm 12.1 \mathrm{~mm} \mathrm{Hg}$ and $10.8 \pm$ 5.0 Wood units, respectively. Fifty-three patients received PDE-5I as monotherapy, while 37 patients received PDE$5 \mathrm{I}$ in addition to other PAH medical therapies including beraprost $(n=13)$, bosentan $(n=23)$, and epoprostenol $(\mathrm{n}=5)$.

Table 2 shows the distributions of the ACE I/D and GNB3 C825T genotypes in PH patients and controls, taken from previous reports of Japanese individuals $[11,17]$. The observed genotype frequencies were in agreement with the frequencies predicted by the Hardy-Weinberg equilibrium equation. The genotype distribution of GNB3 polymorphisms in the patient groups was similar to that in the control group, while that of $A C E$ polymorphisms was significantly different between patients with CTEPH and controls (higher frequency of II genotype, $p=0.048$ ).

No significant differences were observed in the baseline characteristics between patients with the II/TT $(n=15)$ and non-II/TT $(\mathrm{n}=75)$ genotypes, except for higher age in the non-II/TT genotype group ( $\mathrm{p}=0.03$; table 1$)$. The $6 \mathrm{MWD}$, sPpa, BNP, and WHO functional class values improved in both groups after treatment with PDE-5I. There were no significant differences between the two genotype groups in both pre- and post-treatment values, although patients with the II/TT genotype showed a tendency toward longer 6MWD values and lower BNP levels compared to patients with other genotypes after administration of PDE-5I. In addition, the frequency of post-treatment $\mathrm{BNP}<100 \mathrm{pg} / \mathrm{ml}$ was significantly higher in patients with the II/TT genotype compared to those with the non-II/TT genotype ( 84.6 vs. $54.3 \%$, respectively; $\mathrm{p}=0.04$ ). 


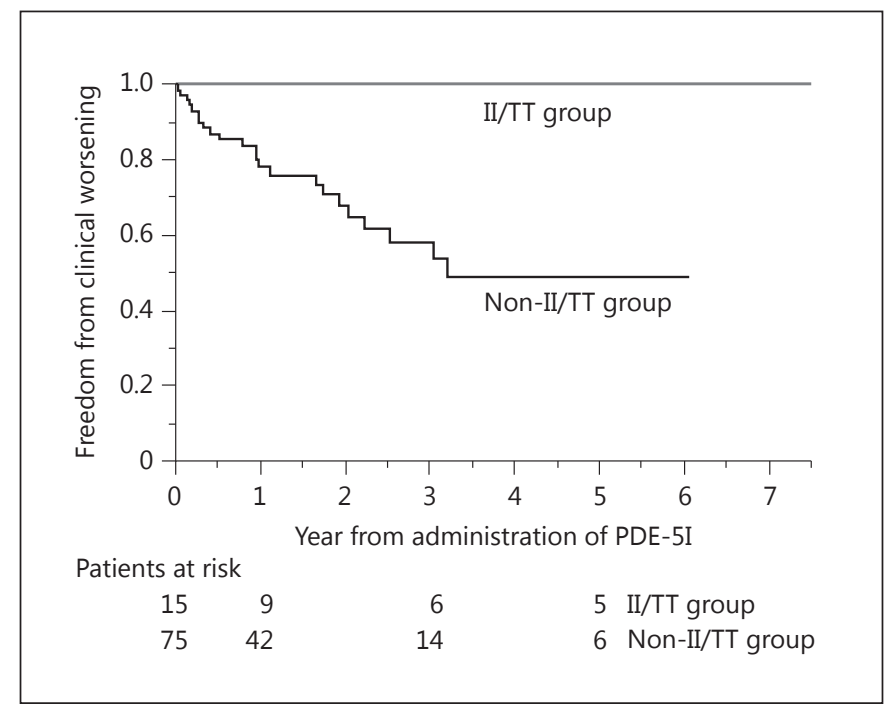

Fig. 1. Comparison of Kaplan-Meier curves of freedom from clinical worsening between patients with the ACE/GNB3 II/TT genotype and patients with the non-II/TT genotypes in the PDE-5I treatment group. Patients with the II/TT genotype showed significantly longer time to clinical worsening than patients with the non-II/TT genotypes (5-year freedom from clinical worsening: 100 vs. $48.6 \%$, respectively; $\mathrm{p}=0.018$ ).

The association between the ACE I/D polymorphism and freedom from clinical worsening in patients treated with PDE-5I was analyzed. The 5-year freedom from clinical worsening rates in the II and ID/DD groups were 67.0 and $42.9 \%$, respectively $(\mathrm{p}=0.17)$. Comparison of the GNB3 TT genotype with the TC/CC genotype in freedom from clinical worsening showed that the TT group exhibited a significantly longer time to clinical worsening than the TC/CC group (5-year freedom from clinical worsening: 78.7 vs. $48.0 \%$, respectively; $\mathrm{p}=0.04)$. The combined effects of $A C E$ and GNB3 polymorphisms showed that no patients with the ACE/GNB3 II/TT genotype $(n=15)$ exhibited clinical worsening. The II/TT group had significantly better clinical courses than the non-II/TT group (5-year freedom from clinical worsening: 100 vs. $48.6 \%$, respectively; $\mathrm{p}=0.018$; fig. 1 ). In addition, in the monotherapy group, patients with the II/ TT genotype also tended to have a longer time to clinical worsening (5-year freedom from clinical worsening: 100 vs. $52.2 \%$, respectively; $p=0.18$ ). In contrast, in the combination therapy group, the II/TT genotype was significantly associated with better clinical course (5-year freedom from clinical worsening: 100 vs. $40.8 \%$, respectively; $\mathrm{p}=0.04)$.

Gene Polymorphisms in PH Patients
Table 2. Frequencies of the $A C E$ and GNB3 polymorphisms in patients and controls

\begin{tabular}{llll}
\hline ACE & II & ID & DD \\
\hline Controls (Tanabe, 2006) & $40(41.2)$ & $42(43.3)$ & $15(15.5)^{*}$ \\
All (n = 90) & $48(53.3)$ & $28(31.1)$ & $14(15.6)^{*}$ \\
CTEPH (n = 58) & $\begin{array}{l}34(58.6) \\
\text { PAH (n = 32) }\end{array}$ & $14(24.1)$ & $10(17.3)^{*}$ \\
GNB3 & TT & TC & CC \\
\hline Controls (Shioji, 2004) & $282(25.5)$ & $536(48.5)$ & $287(26)$ \\
All (n = 90) & $24(26.7)$ & $44(48.9)$ & $22(24.4)$ \\
CTEPH (n= 58) & $18(31)$ & $28(48.3)$ & $12(20.7)$ \\
PAH (n = 32) & $6(18.8)$ & $16(50)$ & $10(31.2)$ \\
\hline
\end{tabular}

Data are the number of subjects with percentages in parentheses. * $\mathrm{p}<0.05$ by $\chi^{2}$ test.

Univariate Cox proportional hazard analysis showed that a higher 6MWD, a lower mean Ppa, a lower PVR, a lower sPpa, and the ACE/GNB3 II/TT genotype were significant predictors of freedom from clinical worsening (table 3). The II/TT genotype was also associated with freedom from clinical worsening when adjusted according to $6 \mathrm{MWD}$ and PVR in multivariate analyses. Furthermore, table 4 showed that the GNB3 genotype (TT vs. TC/ $\mathrm{CC})$ alone had a significant effect on clinical worsening in patients with $\mathrm{PH}$ treated with a PDE-5I (hazard ratio 0.3, $\mathrm{p}=0.03$ ), whereas the $A C E$ genotype (II vs. ID/DD) alone was not associated (hazard ratio $0.56, \mathrm{p}=0.17$ ). However, the combination of two polymorphisms (II/TT vs. nonII/TT) was associated with a substantially improved clinical course (hazard ratio $5.72 \times 10^{-7}, \mathrm{p}=0.002$ ), even after adjustment for age (adjusted hazard ratio $6.31 \times 10^{-7}, \mathrm{p}=$ 0.003 ).

Higher age, lower $\mathrm{PaO}_{2}$, and higher $\mathrm{BNP}$ were observed in patients with CTEPH compared to those with PAH. Table 5 shows baseline characteristics of patients with CTEPH. No significant differences were observed between II/TT and non-II/TT genotypes, except higher age for the non-II/TT genotype (49.5 \pm 10.1 and $59.5 \pm$ 12.3 years, respectively; $\mathrm{p}=0.01$ ). There were no significant differences between the two genotype groups in post-treatment 6MWD, sPpa, and WHO functional class, whereas patients with the II/TT genotype showed lower BNP levels compared with patients having other genotypes after administration of PDE-5I (115 \pm 173 and 275 $\pm 290 \mathrm{pg} / \mathrm{ml}$, respectively; $\mathrm{p}=0.02$ ). 
Table 3. Predictors of freedom from clinical worsening determined by univariate and multivariate Cox proportional hazard analyses

\begin{tabular}{|c|c|c|c|c|c|c|c|c|}
\hline \multirow[t]{2}{*}{ Factor } & \multicolumn{4}{|l|}{ All patients $(n=90)$} & \multicolumn{4}{|c|}{ CTEPH patients $(\mathrm{n}=58)$} \\
\hline & HR (95\% CI) & $\mathrm{p}$ & HR (95\% CI) & $\mathrm{p}$ & HR (95\% CI) & $\mathrm{p}$ & HR (95\% CI) & $\mathrm{p}$ \\
\hline Age & $1.03(0.996-1.066)$ & 0.08 & & & $1.03(0.983-1.082)$ & 0.22 & & \\
\hline Gender (female/male) & 1.66 & 0.33 & & & 1.03 & 0.97 & & \\
\hline PAH:СTEPH & 1.16 & 0.73 & & & & & & \\
\hline $\mathrm{sPpa}(\mathrm{mm} \mathrm{Hg})$ & $1.02(1.002-1.037)$ & 0.03 & & & $1.02(0.995-1.046)$ & 0.12 & & \\
\hline 6MWD (m) & $0.99(0.986-0.996)$ & 0.0007 & $0.99(0.988-1.001)$ & 0.09 & $0.99(0.986-0.999)$ & 0.03 & $1.00(0.990-1.007)$ & 0.71 \\
\hline $\mathrm{CI}\left(\mathrm{l} / \mathrm{min} / \mathrm{m}^{2}\right)$ & $0.47(0.172-1.134)$ & 0.1 & & & $0.51(0.110-1.981)$ & 0.35 & & \\
\hline $\mathrm{PaO}_{2}$ (Torr) & $0.99(0.947-1.027)$ & 0.56 & & & $0.99(0.918-1.064)$ & 0.86 & & \\
\hline Mean Ppa (mm Hg) & $1.07(1.017-1.115)$ & 0.008 & & & $1.03(0.968-1.102)$ & 0.31 & & \\
\hline PVR (Wood unit) & $1.16(1.050-1.268)$ & 0.005 & $1.12(1.007-1.245)$ & 0.04 & $1.15(0.991-1.321)$ & 0.07 & $1.16(0.980-1.391)$ & 0.08 \\
\hline
\end{tabular}

$\mathrm{HR}=$ Hazard ratio; $95 \% \mathrm{CI}=95 \%$ confidence interval; $\mathrm{CI}=$ cardiac index $; \mathrm{PaO}_{2}=$ arterial oxygen tension.

Table 4. Genotype interaction between $A C E$ and GNB3 in relation to clinical worsening

\begin{tabular}{|c|c|c|c|c|c|c|c|c|}
\hline & \multicolumn{4}{|c|}{ All patients $(\mathrm{n}=90)$} & \multicolumn{4}{|c|}{ CTEPH patients $(\mathrm{n}=58)$} \\
\hline & HR & $\mathrm{p}$ & $\begin{array}{l}\text { HR adjusted } \\
\text { by age }\end{array}$ & $\mathrm{p}$ & HR & $\mathrm{p}$ & $\begin{array}{l}\text { HR adjusted } \\
\text { by age }\end{array}$ & $\mathrm{p}$ \\
\hline ACE/GNB3 II/TT (vs. non-II/TT) & $5.72 \times 10^{-7}$ & 0.002 & $6.31 \times 10^{-7}$ & 0.003 & $4.78 \times 10^{-7}$ & 0.005 & $5.32 \times 10^{-7}$ & 0.009 \\
\hline$A C E$ II (vs. ID or DD) & 0.56 & 0.17 & 0.57 & 0.18 & 0.46 & 0.16 & 0.44 & 0.13 \\
\hline GNB3 TT (vs. TC or CC) & 0.3 & 0.03 & 0.33 & 0.06 & 0.46 & 0.20 & 0.55 & 0.37 \\
\hline
\end{tabular}

Patients with the ACE II and GNB3 TT genotypes tended to have better clinical courses than patients with non-II and non-TT genotypes, respectively, but this difference was not significant (5-year freedom from clinical worsening: 73.6 vs. $33.4 \%, p=0.15 ; 72.2$ vs. $49.6 \%, p=$ 0.22 , respectively). However, patients with CTEPH with the II/TT genotype had significantly longer time to clinical worsening than those with the non-II/TT genotype (5-year freedom from clinical worsening: 100 vs. $45.5 \%$, respectively; $\mathrm{p}=0.03$ ) as well as in all $\mathrm{PH}$ patients (fig. 2). Although there was a similar tendency in patients with $\mathrm{PAH}$, this difference was not statistically significant [5year freedom from clinical worsening: $100 \%(n=3)$ vs. $64.8 \%(\mathrm{n}=29)$, respectively; $\mathrm{p}=0.31]$.

As with all patients, the data from univariate and multivariate Cox proportional hazard regression analyses in patients with CTEPH are shown (table 3). Univariate analysis revealed that the $A C E / G N B 3$ genotype and
6MWD were significant predictors of clinical worsening. In addition, gene polymorphism was an independent factor on multivariate analysis. Evaluation of the synergistic effects of the ACE/GNB3 genotype on clinical worsening was also similar for all patients with $\mathrm{PH}$ (table 4 ).

\section{Discussion}

Our results are the first to show that combined $A C E$ I/D and GNB3 C825T polymorphisms were associated with the efficacy of PDE-5I in Japanese patients with PAH or CTEPH. We previously investigated the influence of the GNB3 C825T polymorphism on the efficacy of sildenafil in patients with $\mathrm{PH}$ and found that patients with the TT genotype had a better clinical course than patients with the TC/CC genotype [15]. Although other genetic differences may also contribute to the efficacy of modern 
Table 5. Characteristics of patients with CTEPH

\begin{tabular}{|c|c|c|c|c|}
\hline$A C E / G N B 3$ & $\begin{array}{l}\text { All } \\
(\mathrm{n}=58)\end{array}$ & $\begin{array}{l}\text { II/TT } \\
(\mathrm{n}=12)\end{array}$ & $\begin{array}{l}\text { Non-II/TT } \\
(\mathrm{n}=46)\end{array}$ & $\mathrm{p}$ \\
\hline Age, years & $57.4 \pm 12.5$ & $49.5 \pm 10.1$ & $59.5 \pm 12.3$ & 0.01 \\
\hline Female/male & $45 / 13$ & $9 / 3$ & $36 / 10$ & 0.81 \\
\hline Mean Pra, mm Hg & $6.81 \pm 3.97$ & $5.00 \pm 2.96$ & $7.29 \pm 4.10$ & 0.12 \\
\hline Mean Ppa, mm Hg & $47.5 \pm 11.5$ & $43.8 \pm 5.72$ & $48.5 \pm 12.4$ & 0.11 \\
\hline $\mathrm{CI}, \mathrm{l} / \mathrm{min} / \mathrm{m}^{2}$ & $2.47 \pm 0.55$ & $2.48 \pm 0.36$ & $2.46 \pm 0.60$ & 0.78 \\
\hline PVR, Wood units & $10.9 \pm 4.61$ & $9.94 \pm 2.49$ & $11.1 \pm 5.03$ & 0.33 \\
\hline $\mathrm{PaO}_{2}$, Torr & $56.1 \pm 9.47$ & $58.5 \pm 8.39$ & $55.4 \pm 9.75$ & 0.40 \\
\hline Pretreatment (monotherapy/combination) & $35 / 23$ & $7 / 5$ & $28 / 18$ & 0.87 \\
\hline \multicolumn{5}{|l|}{$6 \mathrm{MWD}, \mathrm{m}$} \\
\hline Before treatment & $342 \pm 97.0$ & $375 \pm 103$ & $333 \pm 94.7$ & 0.23 \\
\hline After treatment & $356 \pm 89.2$ & $404 \pm 57.5$ & $343 \pm 92.6$ & 0.09 \\
\hline$\Delta 6 \mathrm{MWD}$ & $25.7 \pm 47.6$ & $41.6 \pm 59.5$ & $21.0 \pm 43.7$ & 0.59 \\
\hline \multicolumn{5}{|l|}{ sPpa, mm Hg } \\
\hline Before treatment & $84.3 \pm 23.5$ & $79.8 \pm 29.2$ & $85.5 \pm 22.0$ & 0.48 \\
\hline After treatment & $74.9 \pm 25.0$ & $66.5 \pm 38.2$ & $76.9 \pm 21.0$ & 0.45 \\
\hline$\Delta \mathrm{sPpa}$ & $-8.34 \pm 15.6$ & $-5.32 \pm 19.2$ & $-9.07 \pm 14.8$ & 0.52 \\
\hline \multicolumn{5}{|l|}{ WHO functional class (I/II/III/IV) } \\
\hline Before treatment & $0 / 12 / 33 / 13$ & $0 / 3 / 7 / 2$ & $0 / 9 / 26 / 11$ & 0.83 \\
\hline After treatment & $0 / 22 / 35 / 1$ & $0 / 7 / 5 / 0$ & $0 / 15 / 30 / 1$ & 0.25 \\
\hline \multicolumn{5}{|l|}{$\mathrm{BNP}, \mathrm{pg} / \mathrm{ml}$} \\
\hline Before treatment & $387 \pm 462$ & $256 \pm 375$ & $420 \pm 479$ & 0.13 \\
\hline After treatment & $242 \pm 277$ & $115 \pm 173$ & $275 \pm 290$ & 0.02 \\
\hline \multicolumn{5}{|l|}{$\mathrm{BNP}<100 \mathrm{pg} / \mathrm{ml}, \%$} \\
\hline Before treatment & 32.7 & 54.5 & 27.3 & 0.08 \\
\hline After treatment & 43.4 & 81.8 & 33.3 & 0.004 \\
\hline
\end{tabular}

Values are expressed as the mean $\pm \mathrm{SD}$ or $\mathrm{n} . \mathrm{CI}=$ Cardiac index; $\mathrm{PaO}_{2}=$ arterial oxygen tension .

PAH therapies, no further studies have focused on the effects of pharmacogenomic interactions in the treatment of $\mathrm{PH}$. In this study, the GNB3 C825T polymorphism alone significantly affected the efficacy of PDE-5I in the absence of clinical worsening, as described above, whereas the influence of the $A C E \mathrm{I} / \mathrm{D}$ polymorphism alone on the clinical course was not significant. However, the combined effect of the two gene polymorphisms was substantial and significant in a synergistic manner. Moreover, multivariate analysis showed that the combined gene polymorphism was a significant predictor for a better clinical course after initiation of PDE-5I treatment, independent of 6MWD and PVR.

Our findings are consistent with several previous reports. In patients with erectile dysfunction, patients with the GNB3 TT genotype or the ACE II genotype had a better response to sildenafil [14]. However, the mechanism through which these gene polymorphisms affect the PDE-5I response is not well established.

Gene Polymorphisms in PH Patients
PDE-5I targets the NO pathway. NO stimulates dilatation of vascular smooth muscle through the production of cyclic guanosine monophosphate (cGMP) $[6,18]$. Serum and tissue ACE levels in ACE DD carriers are higher than those in individuals with the II genotype $[19,20]$. Moreover, elevated ACE levels enhance the degradation of bradykinin, which stimulates the release of NO from endothelial cells [21].

The GNB3 T allele has been shown to enhance vasoconstriction in response to several factors including angiotensin II, and to promote vasodilation of the human hand vein in response to glyceroltrinitrate [22-24]. These data indicate that gene polymorphisms are associated with vasodilation through the NO pathway and interactions between the renin-angiotensin system and G-protein-mediated signaling.

In the current study, we found that patients with the II/TT genotype tended to have a better clinical course than patients with the non-II/TT genotype in patients re- 


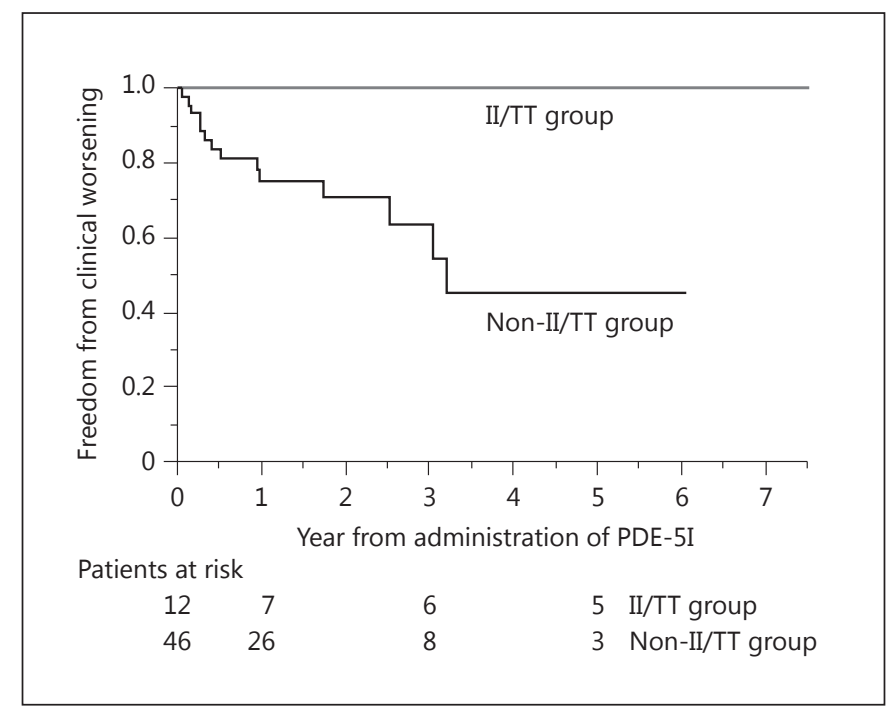

Fig. 2. Comparison of Kaplan-Meier curves of freedom from clinical worsening between patients with the ACE/GNB3 II/TT genotype and patients with the non-II/TT genotypes in the CTEPH group. Patients with the II/TT genotype showed significantly longer time to clinical worsening than patients with the non-II/TT genotypes (5-year freedom from clinical worsening: 100 vs. $45.5 \%$, respectively; $\mathrm{p}=0.03$ ).

ceiving monotherapy. However, in the combination therapy group, the former had a significantly longer time to clinical worsening than the latter. Moreover, we also investigated the association between the gene polymorphisms and the efficacy of bosentan. Clinical worsening occurred in patients with the II/TT genotype and in patients with the non-II/TT genotype $(\mathrm{n}=43$; 3-year absence of clinical worsening: 75.0 vs. $85.5 \%, \mathrm{p}=0.25$; data not shown). These results indicated that the ACE/GNB3 polymorphism may be useful in predicting the efficacy of PDE-5I, regardless of the administration of other vasodilators.

In our study, we could not confirm any significant effects of gene polymorphisms on hemodynamic values, serum BNP levels, WHO functional class, and 6MWD values. However, patients with the II/TT genotype showed a slight tendency to have longer 6MWD values and lower BNP levels than patients with other genotypes after the administration of PDE-5I. In addition, the frequency of $\mathrm{BNP}<100 \mathrm{pg} / \mathrm{ml}$ after PDE-5I treatment was significantly higher in patients with the II/TT genotype than in patients with other genotypes. Moreover, tricuspid annular plane systolic excursion after treatment with PDE-5I was also better in patients with the II/TT genotype (data not shown). Thus, the observed longer time to clinical worsening in patients with the II/TT genotype may be due to improved right ventricular function. For hemodynamic assessments, we measured only sPpa values after PDE-5I treatment. Therefore, further studies are needed to determine the acute effects of gene polymorphisms on the response to PDE-5I.

Although previously there was no reimbursement for PAH drugs for CTEPH until riociguat was covered by insurance, randomized, placebo-controlled trials with bosentan [25] or sildenafil [26] in patients with CTEPH showed significant improvements in pulmonary hemodynamics using these drugs. Although patients with CTEPH exhibit changes in the pulmonary microvasculature similar to those in patients with $\mathrm{PAH}$, the pathogenesis of CTEPH differs from that of PAH. Considering these two distinct medical conditions, we also evaluated the effects of gene polymorphisms in patients with CTEPH alone. Similar to all $\mathrm{PH}$ patients, CTEPH patients with the II/TT genotype had a better clinical course after treatment with PDE-5I compared to that of patients with other genotypes. However, for patients with $\mathrm{PAH}$, this difference did not reach statistical significance, probably due to the small number of patients with the II/TT genotype. In addition, multivariate analysis showed that the $A C E / G N B 3$ genotype was a significant predictor of clinical worsening, even in patients with CTEPH only.

Although associations between these gene polymorphisms and the risk of developing several diseases, such as atherosclerosis, diabetic nephropathy, and essential hypertension, have been reported [8,27], no studies have shown associations between these gene polymorphisms and the development of PH. In this study, the two gene polymorphisms were not associated with the risk of $\mathrm{PH}$ and $\mathrm{PAH}$. While we observed a higher frequency of the $A C E$ II genotype in patients with CTEPH, this difference in our study may have resulted from sample bias due to the small number of patients, because our previous study, which included 95 patients with CTEPH, did not show those differences [11].

In recent years, the long-term effects of certain drugs have become difficult to evaluate due to the popularization of upfront combination therapy in PAH. However, upfront combination therapy is expensive and may not be accepted in every county. Therefore, additional studies are needed to determine the most effective drugs based on the status of gene polymorphisms.

The main limitation of this study was its design as a retrospective observational study performed at a single institution. Therefore, retrieval bias may have been pres- 
ent because data were collected from clinical records that had different degrees of completeness. Moreover, there were no untreated control groups for definitely worse prognosis. It is possible that confounding factors could have influenced our results; however, baseline characteristics did not differ significantly between the two genotype groups. Another limitation was that the number of patients was relatively small when patients were divided into groups based on disease category or pretreatment. Additional studies with more patients are needed to confirm our results, particularly in patients with $\mathrm{PAH}$. Despite these limitations, no patients with the $A C E / G N B 3$ II/TT genotype exhibited clinical worsening after initiation of PDE-5I in our study. Although each polymorphism alone could be an independent predictor of a better clinical course, combination analysis of gene polymorphisms may be more helpful for determining the appropriate treatment regimen in patients with $\mathrm{PH}$, thereby improving efficacy and reducing costs.
In conclusion, the combination of $A C E$ and GNB3 polymorphisms was associated with the efficacy of PDE5I in the treatment of $\mathrm{PH}$.

\section{Acknowledgments}

The present study was supported in part by a grant to the Respiratory Failure Research Group from the Ministry of Health, Labour and Welfare of Japan, and a research grant from the Ministry of Education, Culture, Sports, Science and Technology of Japan (25461148).

\section{Financial Disclosure and Conflicts of Interest}

N.T. received honoraria for lectures from Actelion and Pfizer. K.T. received honoraria for lectures from Actelion. N.T., R.N., A.S. and T.J. belong to the endowed department sponsored by Actelion.

\section{References}

1 Fukumoto Y, Shimokawa H: Recent progress in the management of pulmonary hypertension. Circ J 2011;75:1801-1810.

-2 Galie N, Hoeper MM, Humbert M, Torbicki A, Vachiery JL, Barbera JA, Beghetti M, Corris P, Gaine S, Gibbs JS, Gomez-Sanchez MA, Jondeau G, Klepetko W, Opitz C, Peacock A, Rubin L, Zellweger M, Simonneau G; ESC Committee for Practice Guidelines: Guidelines for the diagnosis and treatment of pulmonary hypertension: the task force for the diagnosis and treatment of pulmonary hypertension of the European Society of Cardiology (ESC) and the European Respiratory Society (ERS), endorsed by the International Society of Heart and Lung Transplantation (ISHLT). Eur Heart J 2009;30:2493-2537.

-3 Simonneau G, Gatzoulis MA, Adatia I, Celermajer D, Denton C, Ghofrani A, Gomez Sanchez MA, Krishna Kumar R, Landzberg M, Machado RF, Olschewski H, Robbins IM, Souza R: Updated clinical classification of pulmonary hypertension. J Am Coll Cardiol 2013;62:D34-D41.

-4 Hoeper MM, Mayer E, Simonneau G, Rubin LJ: Chronic thromboembolic pulmonary hypertension. Circulation 2006;113:2011-2020.

5 Pepke-Zaba J, Delcroix M, Lang I, Mayer E, Jansa P, Ambroz D, Treacy C, D’Armini AM, Morsolini M, Snijder R, Bresser P, Torbicki A, Kristensen B, Lewczuk J, Simkova I, Barbera JA, de Perrot M, Hoeper MM, Gaine S, Speich R, Gomez-Sanchez MA, Kovacs G, Hamid AM, Jais X, Simonneau G: Chronic thromboembolic pulmonary hypertension (CTEPH): results from an international prospective registry. Circulation 2011;124:1973-1981.

6 Archer SL, Michelakis ED: Phosphodiesterase type 5 inhibitors for pulmonary arterial hypertension. N Engl J Med 2009;361:18641871.

7 Lindpaintner K, Pfeffer MA, Kreutz R, Stampfer MJ, Grodstein F, LaMotte F, Buring J, Hennekens $\mathrm{CH}$ : A prospective evaluation of an angiotensin-converting enzyme gene polymorphism and the risk of ischemic heart disease. N Engl J Med 1995;332:706-711.

8 Sayed-Tabatabaei FA, Oostra BA, Isaacs A, van Duijn CM, Witteman JC: Ace polymorphisms. Circ Res 2006;98:1123-1133.

-9 Hamelin BA, Zakrzewski-Jakubiak M, Robitaille NM, Bogaty P, Labbe L, Turgeon J: Increased risk of myocardial infarction associated with angiotensin-converting enzyme gene polymorphism is age dependent. J Clin Pharmacol 2011;51:1286-1292.

10 Rigat B, Hubert C, Corvol P, Soubrier F: PCR detection of the insertion/deletion polymorphism of the human angiotensin converting enzyme gene (DCP1) (dipeptidyl carboxypeptidase 1). Nucleic Acids Res 1992;20:1433.

11 Tanabe N, Amano S, Tatsumi K, Kominami S, Igarashi N, Shimura R, Matsubara H, Kasahara Y, Takiguchi Y, Kuriyama T: Angiotensin-converting enzyme gene polymorphisms and prognosis in chronic thromboembolic pulmonary hypertension. Circ J 2006;70: 1174-1179.

12 Siffert W, Rosskopf D, Siffert G, Busch S, Moritz A, Erbel R, Sharma AM, Ritz E, Wich- mann HE, Jakobs KH, Horsthemke B: Association of a human G-protein beta3 subunit variant with hypertension. Nat Genet 1998; 18:45-48.

13 Bae Y, Park C, Han J, Hong YJ, Song HH, Shin ES, Lee JE, Han BG, Jang Y, Shin DJ, Yoon SK: Interaction between GNB3 c825t and ACE I/D polymorphisms in essential hypertension in Koreans. J Hum Hypertens 2007;21:159-166.

14 Eisenhardt A, Siffert W: Genetic risk factors for erectile dysfunction and genetic determinants of drug response - on the way to improve drug safety? Herz 2003;28:304-313.

-15 Sekine A, Tanabe N, Sugiura T, Shigeta A, Jujo T, Nishimura R, Sakao S, Kasahara Y, Tatsumi K: Polymorphism of the $G$ protein beta 3 subunit gene influences the efficacy of sildenafil in patients with pulmonary hypertension. Intern Med 2014;53:291-297.

16 Koch W, Latz W, Eichinger M, Ganser C, Schomig A, Kastrati A: Genotyping of the angiotensin I-converting enzyme gene insertion/deletion polymorphism by the TaqMan method. Clin Chem 2005;51:1547-1549.

17 Shioji K, Kokubo Y, Mannami T, Inamoto N, Morisaki H, Mino Y, Tagoi N, Yasui N, Iwaii $\mathrm{N}$ : Association between hypertension and the alpha-adducin, beta1-adrenoreceptor, and Gprotein beta3 subunit genes in the Japanese population; the Suita study. Hypertens Res 2004;27:31-37.

18 Ramani GV, Park MH: Update on the clinical utility of sildenafil in the treatment of pulmonary arterial hypertension. Drug Des Devel Ther 2010;4:61-70. 
19 Rigat B, Hubert C, Alhenc-Gelas F, Cambien F, Corvol P, Soubrier F: An insertion/deletion polymorphism in the angiotensin I-converting enzyme gene accounting for half the variance of serum enzyme levels. J Clin Invest 1990;86:1343-1346.

20 Danser AH, Schalekamp MA, Bax WA, van den Brink AM, Saxena PR, Riegger GA, Schunkert H: Angiotensin-converting enzyme in the human heart. Effect of the Deletion/Insertion polymorphism. Circulation 1995;92:1387-1388.

- 21 Becker AJ, Uckert S, Stief CG, Truss MC, Machtens S, Scheller F, Knapp WH, Hartmann U, Jonas U: Possible role of bradykinin and angiotensin II in the regulation of penile erection and detumescence. Urology 2001;57: 193-198.
22 Siffert W: Cardiovascular pharmacogenetics: on the way toward individually tailored drug therapy. Kidney Int Suppl 2003;S168-S171.

23 Wenzel RR, Siffert W, Bruck H, Philipp T, Schafers RF: Enhanced vasoconstriction to endothelin-1, angiotensin II and noradrenaline in carriers of the GNB3 $825 \mathrm{~T}$ allele in the skin microcirculation. Pharmacogenetics 2002;12:489-495.

24 Torfgard K, Ahlner J, Axelsson KL: Relaxation of bovine mesenteric arteries by glyceryl trinitrate and other nitro-compounds: evidence for partly different mechanisms of action. Pharmacol Toxicol 1990;67:216-221.

25 Jais X, D’Armini AM, Jansa P, Torbicki A, Delcroix M, Ghofrani HA, Hoeper MM, Lang IM, Mayer E, Pepke-Zaba J, Perchenet L, Morganti A, Simonneau G, Rubin LJ: Bosentan for treatment of inoperable chronic thromboembolic pulmonary hypertension: benefit (bosentan effects in inoperable forms of chronic thromboembolic pulmonary hypertension), a randomized, placebo-controlled trial. J Am Coll Cardiol 2008;52:2127-2134.

26 Suntharalingam J, Treacy CM, Doughty NJ, Goldsmith K, Soon E, Toshner MR, Sheares KK, Hughes R, Morrell NW, Pepke-Zaba J: Long-term use of sildenafil in inoperable chronic thromboembolic pulmonary hypertension. Chest 2008;134:229-236.

27 Zheng H, Xu H, Cui B, Xie N, Wang Z, Luo M: Association between polymorphism of the G-protein beta3 subunit C825T and essential hypertension: an updated meta-analysis involving 36,802 subjects. Biol Res 2013;46: 265-273. 